\title{
Identification of Differentially Expressed Tear Proteins after Corneal Reconstruction with DPSIS Graft in Dogs Suffering from Keratoconjunctivitis Sicca
}

\author{
Sowbharenya Chelladurai ${ }^{1}$, Kiranjeet Singh ${ }^{1}$, Aswathy Gopinathan ${ }^{1 *}$, Ravi Kant Agrawal ${ }^{2}$, Ajay Kumar ${ }^{3}$, \\ Pawan Kumar ${ }^{4}$ and Monalisa Sahoo ${ }^{4}$ \\ ${ }^{1}$ Division of Surgery, ICAR-IVRI, Izatnagar, Bareilly, Uttar Pradesh, INDIA \\ ${ }^{2}$ Division of Livestock Products technology, ICAR-IVRI, Izatnagar, Bareilly, Uttar Pradesh, INDIA \\ ${ }^{3}$ Division of Biochemistry, ICAR-IVRI, Izatnagar, Bareilly, Uttar Pradesh, INDIA \\ ${ }^{4}$ Division of Pathology, ICAR-IVRI, Izatnagar, Bareilly, Uttar Pradesh, INDIA \\ *Corresponding author: A Gopinathan; E-mail: aswathykiran77@gmail.com
}

Received: 24 Feb., 2021

Revised: 16 March, 2021

Accepted: 23 March, 2021

\begin{abstract}
Differentially expressed tear proteins after corneal reconstruction with decellularized porcine small intestinal sub mucosa (DPSIS) in Keratoconjunctivitis sicca (KCS) affected dogs was explored through Matrix Assisted Laser Desorption/Ionization Mass spectrometry (MALDI-TOF/MS) followed by Peptide mass fingerprinting (PMF). Anterior lamellar keratoplasty followed by DPSIS graft was performed in seven dogs with corneal ulcer (group A) and in nine dogs with corneal ulcer as a complication of KCS (group B). Tear was also collected from 12 healthy dogs with no ocular pathology. PMF based protein identification was performed on tryptic peptides of tear film trapped in major bands of ID-SDS PAGE (in duplicate) using MALDI-TOF/ MS. PMF revealed 432 unique tear proteins from major gel bands of DPSIS treated dogs (group A and B) and normal tear from healthy dogs. Based on MOWSE score, relative abundance of proteins in both groups were compared with that in normal tear. Proteins USP37, KRT1, Major allergen Can F1, CCDC39, PRKCD, Serum albumin, TERT and CD163 were found to be significantly $(\mathrm{p}<0.001)$ down-regulated in group A and group B compared to normal tear from healthy dogs. Protein INVS was found significantly up regulated $(\mathrm{p}<0.001)$ in Group B post DPSIS graft compared to pre-operative tear. ZNF252 was found significantly up regulated $(\mathrm{p}<0.001)$ in Group A tear film post-operatively compared to pre-operative tear. Intrinsic cellular stress disrupting DNA replication and cell division, cellular senescence and apoptosis were found as key events underlying corneal pathology in KCS which needs consideration while attempting surgical reconstruction of cornea using DPSIS graft.
\end{abstract}

\section{HIGHLIGHTS}

0 Differentially expressed tear proteins post- DPSIS graft in KCS affected dogs were elucidated.

O Intrinsic cellular stress disrupting DNA replication and cell division was the key event underlying corneal pathology in KCS affected dogs.

Keywords: Tear Proteome, MALDI-TOF/MS, DPSIS graft, Keratoconjunctivitis sicca, Dogs

Porcine small intestinal submucosa (PSIS) is a versatile biomaterial extensively used as corneal graft material in canine and feline cases. It is particularly useful for melting corneal ulcer, wherein corneal stroma is destroyed by enzymatic lysis aided by matrix metalloproteases (Andrade et al., 1999). Many authors attribute a high success rate to corneal surface reconstruction with PSIS graft with minimum complications (Goulle, 2012; Singh et al., 2016; Sowbharenya et al., 2019). Corneal graft

How to cite this article: Chelladurai, S., Singh, K., Gopinathan, A. Agrawal, R.K., Kumar, A., Kumar, P. and Sahoo, M. (2021). Identification of differentially expressed tear proteins after corneal reconstruction with DPSIS graft in dogs suffering from Keratoconjunctivitis sicca. J. Anim. Res., 11(2): 273-283.

Source of Support: None; Conflict of Interest: None 
acceptance depends largely on the healthy corneal tissue around the graft. Rejection rate of inflamed or immunecompromised graft beds is quite high despite aggressive therapy with immune-suppressants (Featherstone et al., 2001). Keratoconjunctivitis sicca is an immune mediated disease targeted to lacrimal gland, characterised by a pathological reduction in aqueous component of tear film and concomitant pathological changes in ocular surface, keratitis, neovascularisation and corneal epithelial defects (Kim et al., 2009, John et al, 2018, Swapna et al., 2020, Kumar et al., 2020, John et al., 2020). Earlier study with PSIS graft showed pronounced corneal pigmentation in brachycephalic dogs with deep corneal ulcer (Goulle, 2012, John et al, 2018, Swapna et al., 2020). Detailed investigation into molecular mechanism underlying fate of corneal graft in immune-mediated disease like $\mathrm{KCS}$ is rare in literature. Proteomic analysis of tear fluid has proven to be a promising tool to gain information about the pathogenesis of diseases (Farias et al., 2013). The current study was therefore undertaken to identify differentially expressed tear proteins after DPSIS grafting in Keratoconjunctivitis sicca (KCS) affected dogs.

\section{MATERIALS AND METHODS}

The study was conducted on sixteen client owned dogs presented to Referral Veterinary Polyclinic cum TVCC, IVRI, Izatnagar, Bareilly, Uttar Pradesh with varying degrees of corneal epithelial defect. Two groups were constituted wherein Group A consisted of seven dogs with corneal defect due to injury / dermoid and Group B consisted of nine dogs having corneal ulcer as complication of KCS. Tear collected from 12 healthy dogs with no ocular pathology were also utilised for this study. Detailed ophthalmic examination protocols were carried out with tonometer (Schiőtz C, Riester, Germany) Direct ophthalmoscope (Reister, Germany), indirect ophthalmoscope (Appasamy Associates, Chennai) with a 20D indirect lens (Volk optical Inc,USA), Slit lamp Biomicroscope (Appasamy Associates, Chennai), Goniolens (OptiTech eye care, Tarun enterprises, Allahabad) along with Schirmer tear test strips (STT) (Schirmer tear test ophthalmic strips, (OptiTech eye care, tarun enterprises, Allahabad) and fluorescein staining (OptiTech eye care, Tarun enterprises, Allahabad) to assess the integrity of corneal surface. Due permission to conduct the clinical study was obtained from Committee for the Purpose of Control and Supervision of Experiments on Animals, Ministry of environment, Forest and climate change, Government of India (No.F.25/33/2016-CPCSEA dated 16/02/2017). Written consent of the owner was taken for operative procedures as well as for pre- and post-operative ocular surface epithelial cells collection.

\section{Surgical intervention and postoperative evaluation}

Food and water were withheld for 12 hours prior to anaesthesia. Topical antibiotic (Ofloxacin - Zenfox, Mankind Pharma Ltd, New Delhi)), anti-inflammatory (Flurbiprofen - Flur, Allergen India Pvt. Ltd.) drops were instilled 6 to 24 hours prior to surgery. Surgery was performed under routine general anaesthesia and local instillation of proparacaine eye drops (Propcaine, Cipla ltd, India). Ocular surface of operated eyes was douched with $0.2 \%$ povidone iodine solution prior to surgery. Under general anaesthesia, loosely adhered corneal epithelium was removed with fine colibri forceps and keratotome $(3.2 \mathrm{~mm})$. A corneal trephine $(6 \mathrm{~mm})$ was used to outline the lamellar keratectomy margins. Anterior lamellar keratectomy was performed with corneal trephine approximately of the same size as that of DPSIS graft. The grafts were secured with simple interrupted sutures using $8 / 0$ polyglactin 910 . Subconjunctival injection of Gentamicin and Dexamethasone was given immediately after surgery. Temporary tarsorraphy was done using 2-0 polyamide after DPSIS graft in both groups. Antibiotic (Ceftriaxone sodium, Monodef, Aristo Pharmaceutical Pvt. Ltd., India @ 20 mg/ kg body weight) and antiinflammatory agent (Meloxicam- M-cam, Unichem Pharmaceuticals, India @ 0.05 mg/kg body weight) was administered intramuscular postoperatively for 5 day. Antibiotic(Ofloxacin-Zenfox, Mankind Pharma Ltd, New Delhi)), anti-inflammatory (Flurbiprofen - Flur, Allergen India Pvt. Ltd.) and topical cyclosporin drops (Hydroeyes $0.05 \% \mathrm{w} / \mathrm{v}$, Lupin Ltd., Mumbai) were instilled thrice daily for four weeks. Tarsorrhapy sutures were removed on $15^{\text {th }}$ postoperative day. The efficacy of the bio-engineered PSIS for reconstruction of corneal defects was evaluated on 15,30 and 60 days postoperatively.

\section{ID Electrophoresis and MALDI-TOF MS}

Tear samples were collected from dogs of group A and B and were kept in $0.5 \mathrm{ml}$ Eppendorf tubes and were frozen 
at $-60^{\circ} \mathrm{C}$, until tear proteomics study. Tear samples were also collected from healthy dogs using same method. After incubation with $10 \mu 150 \mathrm{nM}$ PBS elution buffer and protease inhibitor cocktail at $4^{\circ} \mathrm{C}$ for $20 \mathrm{~h}$, tear fluid was eluted from STT strips by centrifugation@15000 rpm/ min at $4^{\circ} \mathrm{C}$. Total protein concentration in the pooled tear sample of each group was measured by the BCA method (GeNei ${ }^{\mathrm{TM}}$, Bangalore). Based on the protein concentration, the remaining pooled tear samples were diluted to final concentration of $30 \mu \mathrm{g} / 10 \mu \mathrm{l}$ with sterile distilled water. The tear samples were reduced in DTT, mixed with loading buffer; each sample containing $30 \mu \mathrm{g}$ proteins was loaded and run in $12 \%$ polyacrylamide gel along with popular molecular weight marker $(12 \mathrm{kDa}$ to $100 \mathrm{kDa})$. Protein bands were detected by Coomassie Colloidal Blue. Tryptic peptides from at least 4 gels each from group A and Group B (in triplicates) before and after DPSIS graft were subjected to MALDI-TOF/MS and internally calibrated spectra were acquired on a Bruker Daltonics model Ultraflex II Spectrometer. Mass spectra generated were used for PMF search with MASCOT and MS-FIT against Swissprot 2017-06 database with following parameters: global modification of carbamidomethyl (C); possible modification as oxidation (M), Peptide mass tolerance of $300 \mathrm{ppm}$, Fragment mass tolerance of $0.1 \mathrm{Da}$ and 1 missed cleavage. Proteins were identified based on MOWSE score $(>69)$ and those proteins found common in both groups with respect to normal tear were identified and their relative abundance was calculated based on MOWSE score. Protein ontology classification was performed by importing all identified proteins using software Protein Atlas Through Evolutionary Relationship (PANTHER) classification system (http://www.pantherdb.org/, SRI International, Menlo Park, CA). Data were analyzed by software Statistical Program for Social Sciences (SPSS 20 IBM). Statistical analysis of proteomic data is represented as mean $\pm \mathrm{SE}$ of MOWSE score based on the mass/charge of tryptic peptides. Non-parametric data were analysed using Kruskal-Wallis test, $\mathrm{p}<0.05$ was considered to be statistically significant. All the graphs were prepared in Graph Pad Prism (Version 5). Protein ontology analysis was performed by importing all identified proteins using software Protein Atlas Through Evolutionary Relationship (PANTHER) classification system (http://www.pantherdb. org/, SRI International, Menlo Park, CA). Statistical overrepresentation of proteins identified against reference data of Canis lupus familiaris for non random association between the two sets was performed in the same software using Fischer exact test with $\mathrm{P}<0.05$.

\section{RESULTS AND DISCUSSION}

Demographic data of groups A and B (16 cases) is given in Table 1. Group B corneal ulcer cases with KCS pathology were mostly Pugs where as other breeds like Pomeranian, Spitz and Labrador were included in groups A. Age of

Table 1: Demographic data of Group A and Group B dogs subjected to DPSIS graft

\begin{tabular}{llllll}
\hline Animal no. & Breed & Age & Gender & OD/OS & Primary lesion \\
\hline A-1 & Pomeranian & 4 years & Female & OD & Deep stromal ulcer, AC not visible \\
A-2 & French Mastiff & $2 \frac{1}{2}$ years & Male & OD & Deep stromal ulcer, AC not visible \\
A-3 & Mongrel & 7 months & Female & OD & Deep stromal ulcer, AC not visible \\
A-4 & Labrador & $6 \frac{1}{2}$ years & Male & OS & Deep stromal ulcer, AC not visible \\
A-5 & Mongrel & 6 months & Male & OS & Deep stromal ulcer \\
A-6 & Mongrel & 2 years & Male & OD & Deep stromal ulcer \\
A-7 & Spitz & 4 years & Male & OD & Melting ulcerative keratitis \\
B-1 & Pug & 6 months & Female & OS & Deep stromal ulcer \\
B-2 & Pug & $2 \frac{1}{2}$ years & Male & OD & Melting ulcerative keratitis \\
B-3 & Pug & 4 years & Male & OD & Corneal perforation \\
B-4 & Pug & $91 / 2$ months & Female & OD & Corneal perforation \\
B-5 & Pug & 8 months & Male & OS & Corneal perforation \\
B-6 & Pug & $31 / 2$ years & Female & OS & Deep stromal ulcer \\
B-7 & Pug & $3 \frac{1}{2}$ years & Female & OD & Corneal perforation \\
B-8 & Pug & 5 years & Male & OS & Staphyloma \\
B-9 & Pug & $1 \frac{1}{2}$ years & Female & OS & Deep stromal ulcer
\end{tabular}


dogs under this study ranged from seven months to six and a half years in group A (mean \pm S.E. value of age 3.75 \pm 1.05 years) and from six months to five years in group B (mean \pm S.E. value of age $2.44 \pm 0.55$ years).

Average protein concentration was $42.5 \mu \mathrm{g}, 36.5 \mu \mathrm{g}, 31$ $\mu \mathrm{g}$ and $16.5 \mu \mathrm{g}$ in group A and $35 \mu \mathrm{g}, 2 \mu \mathrm{g}, 30 \mu \mathrm{g}$ and 14 $\mu \mathrm{g}$ in Group B per $10 \mu \mathrm{l}$ of pooled tear before graft and 15 , 30 and $60^{\text {th }}$ day post-DPSIS grafting. ID electrophoresis revealed differential expression of tear proteins trapped in ID gel $(30 \mu \mathrm{g} / \mathrm{lane})$ at different post DPSIS graft intervals (day 15, 30 and 60) compared to pre-op tear (Fig. 1a \&1b).

MALDI-TOF/MS revealed 432 unique tear proteins from major gel bands of DPSIS treated dogs (group A and B) and normal tear from healthy dogs. Overlap of common and unique proteins in Group A and Group B before and after DPSIS graft with that in normal tear was pictorially depicted by Venn diagram (Fig. 2). Abundance of proteins for biomarker discovery and elucidation of disease mechanisms is adequately explored through tear film in previous studies (Winiarczyk et al., 2015; Jung et al., 2017). There were 58 proteins common among the two groups (pre and post treatment) and normal tear. MOWSE score for proteins USP 37, KRT1, Major allergen Can F1, CCDC39, PRKCD, Serum albumin, TERT and CD163 were found to be significantly $(p<0.001)$ low in group A (pre op) and group B (pre and post -op) compared to normal tear (Fig. 3). Krt10 and its type II pair Krtl were considered to be keratinisation markers (Toivola et al., 2015) and KRT1 regulates the activity of PKC \& SRS kinases via binding to ITB1 and RACK1(Pekny and Lane,
2007) and elicits unfolded protein response (UPR) (Allen et al., 2016). USP37 has been implicated in X-linked retinal disorders in human (Deborah et al., 1996). Genome-wide association studies (GWAS) implicating the role of the collagen and extracellular matrix pathways in the regulation of keratoconus has identified USP37, ZNF469 and many other genes (Gao et al., 2013; Lu et al., 2013). TERT, the catalytic subunit of telomerase, inhibited apoptosis and augmented DNA repair (Colitz, 2006). Telomerase activity was found to protect replicative senescence and extends life span of keratinocyte stem cells and conjunctival cells (Pellegrini et al., 2004). Major allergen Can f1 (Can F1) is an extracellularly secreted protein structurally homologous to LCN1, the human tear lipocalin. Proteomic analysis of tear film in human dry eye syndrome also showed down regulation of LCN1 (Jung et al., 2017; Huang et al., 2018).

Protein Inversin (INVS) score was found significantly high $(\mathrm{p}<0.001)$ in Group B post DPSIS graft compared to Pre-operative tear (Fig. 3a) and that of ZNF252 was found significantly high $(\mathrm{p}<0.001)$ in Group A post DPSIS graft compared to Pre-operative tear (Fig. 3b). INVS acts as a molecular switch between different Wnt signalling pathways; it inhibited the canonical Wnt pathway and was found associated with abnormality of retinal pigment epithelium (May-Simera et al., 2018). It also influences ciliary disassembly by regulating Wnt signalling (Simons et al., 2005). Serum albumin was significantly unregulated $(\mathrm{p}<0.001)$ in group A (pre op) compared to group B (preop). Functional enrichment of differentially expressed

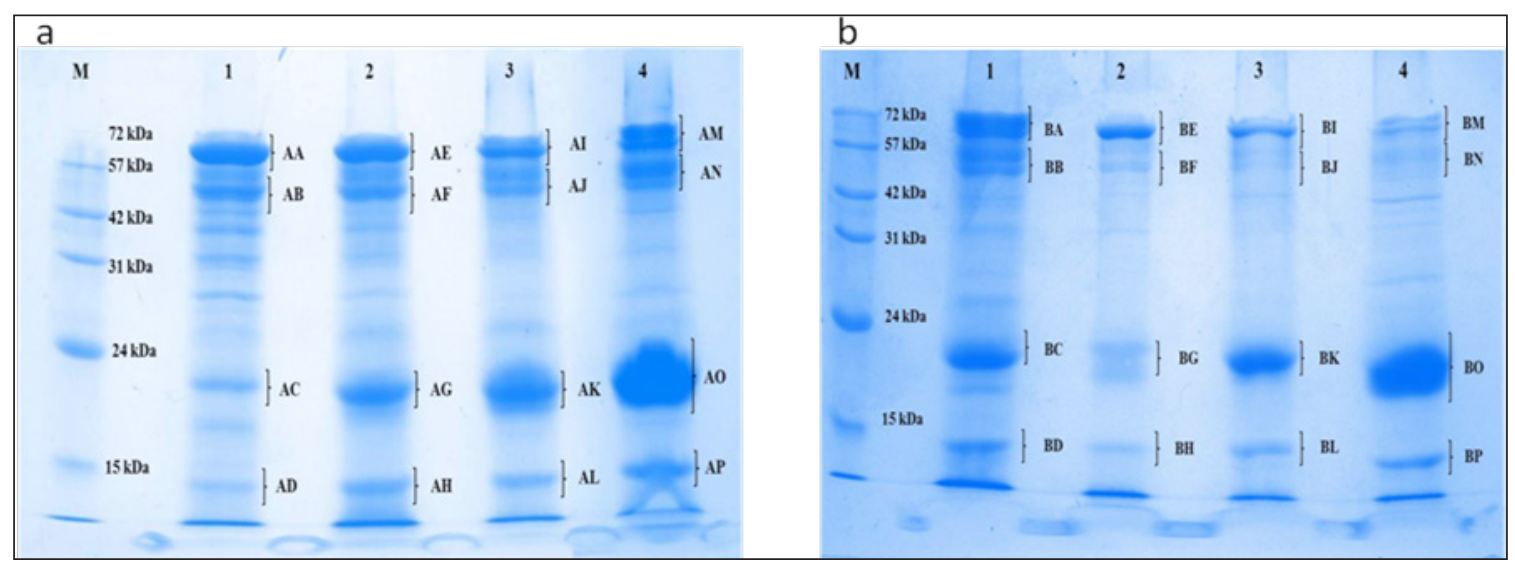

Fig. 1: Coomassie blue-stained SDS-PAGE of tear proteins (M-protein ladder, 1-pre op tear, 2- post DPSIS graft day 15, 3- post DPSIS graft day 30, 4- post DPSIS graft day 60) in Group A (a) and in Group B (b) 


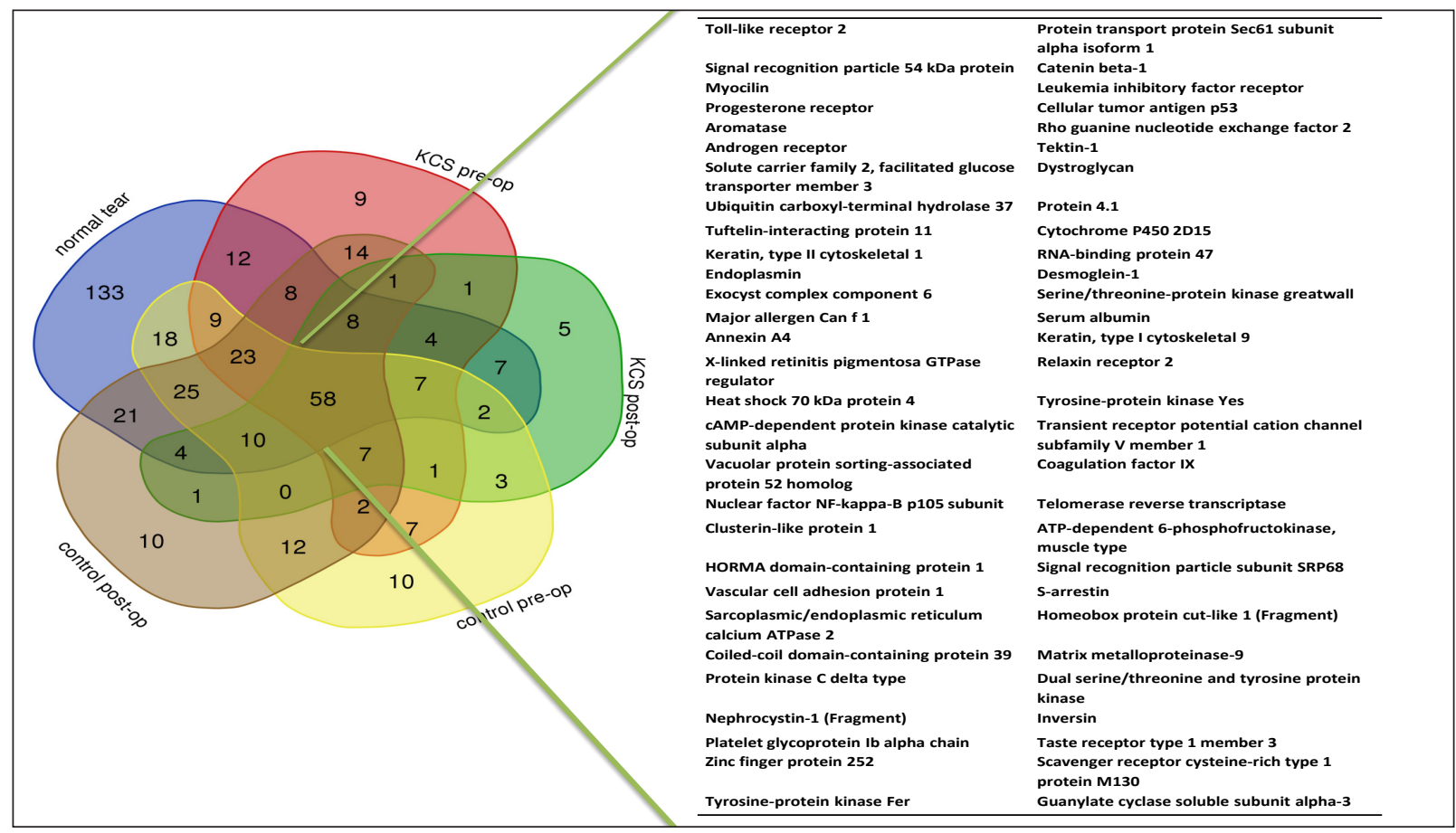

Fig. 2: Venn diagram showing overlaps of common and unique proteins in 2 technical replicates of tear in ID-SDS PAGE gel: normal tear, control pre and post DPSIS graft (group A), KCS pre and post DPSIS graft (group B)

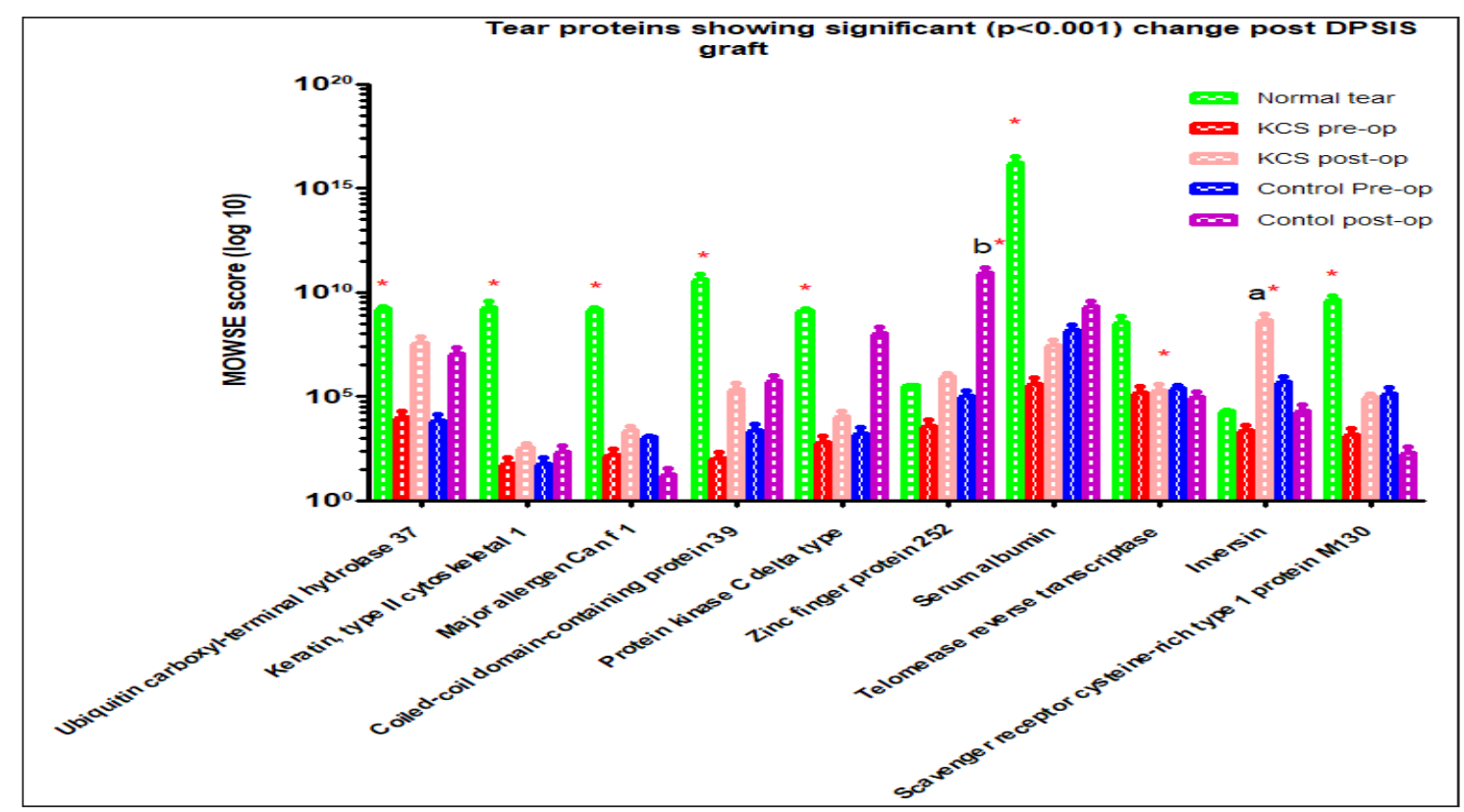

Fig. 3: Differentially expressed tear proteins by MALDI TOF/MS in Group A and Group B before and after DPSIS graft in comparison to tear from healthy dogs; significant difference $(\mathrm{p}<0.001)$ between groups is depicted by asterisk mark, superscript a indicates significant increase in protein score (0.001) of protein INVS between KCS graft post op compared to KCS pre-op (a), superscript b indicates significant increase in protein score (0.001) of Zinc finger protein 252 between Control graft post op compared to Control graft pre-op (b) 
proteins showed cellular process as major Biological process and Binding as the major Molecular function.

Most confident tear proteins were identified by the peptide mass fingerprinting output from 36 major bands through MALDI-TOF/MS analysis and MASCOT (Matrix Science) sequence matching software with Swissprot
2017. 06 database (Table 2). TRAM1, WDR46, Major allergen Can $\mathrm{f} 1$ and HGF were the most confident and highly scoring proteins of major protein bands of normal tear. Major allergen Can $\mathrm{f} 1$ was consistently expressed as tear protein of $24 \mathrm{kDa}$ gel band in normal and group A tear film whereas there was down regulation of this protein in group B tear before and after DPSIS grafting up to $15^{\text {th }}$

Table 2: Tear proteins with highest score and hence most confident ones in different gel bands of ID-SDS PAGE identified by MALDI-TOF PMF and MASCOT search

\begin{tabular}{|c|c|c|c|c|}
\hline Band ID & Protein band & MASCOT search homology & Molecular weight (Da) & MASCOT Score \\
\hline NA & $\sim 72 \mathrm{KDa}$ & Translocating chain-associated membrane protein 1 & 43304 & 76 \\
\hline NB & $\sim 57 \mathrm{KDa}$ & WD repeat-containing protein 46 & 69116 & 54 \\
\hline $\mathrm{NC}$ & $\sim 24 \mathrm{KDa}$ & Major allergen Can $\mathrm{f} 1$ & 19407 & 45 \\
\hline ND & $\sim 15 \mathrm{KDa}$ & Hepatocyte growth factor & 85625 & 84 \\
\hline AA & $\sim 72 \mathrm{KDa}$ & WD repeat-containing protein 46 & 69116 & 47 \\
\hline $\mathrm{AB}$ & $\sim 57 \mathrm{KDa}$ & NAD-dependent protein deacylase sirtuin-5, mitochondrial & 34547 & 48 \\
\hline $\mathrm{AC}$ & $\sim 24 \mathrm{KDa}$ & Major allergen Can f 1 & 19487 & 42 \\
\hline $\mathrm{AD}$ & $\sim 15 \mathrm{KDa}$ & Vascular cell adhesion protein 1 & 82501 & 46 \\
\hline $\mathrm{AE}$ & $\sim 72 \mathrm{KDa}$ & Serum albumin & 70556 & 42 \\
\hline $\mathrm{AF}$ & $\sim 57 \mathrm{KDa}$ & WD repeat-containing protein 46 & 69116 & 60 \\
\hline $\mathrm{AG}$ & $\sim 24 \mathrm{KDa}$ & Major allergen Can $\mathrm{f} 1$ & 19407 & 51 \\
\hline $\mathrm{AH}$ & $\sim 15 \mathrm{KDa}$ & Arylsulfatase I & 64763 & 46 \\
\hline AI & $\sim 72 \mathrm{KDa}$ & B-lymphocyte antigen CD20 & 33319 & 56 \\
\hline AJ & $\sim 57 \mathrm{KDa}$ & $\mathrm{C}-\mathrm{C}$ motif chemokine 17 & 11273 & 44 \\
\hline $\mathrm{AK}$ & $\sim 24 \mathrm{KDa}$ & Major allergen Can f 1 & 19407 & 139 \\
\hline $\mathrm{AL}$ & $\sim 15 \mathrm{KDa}$ & Tyrosine-protein kinase Yes & 60717 & 57 \\
\hline $\mathrm{AM}$ & $\sim 72 \mathrm{KDa}$ & NAD-dependent protein deacylase sirtuin-5 & 34547 & 56 \\
\hline AN & $\sim 57 \mathrm{KDa}$ & Telomerase reverse transcriptase & 126684 & 53 \\
\hline $\mathrm{AO}$ & $\sim 24 \mathrm{KDa}$ & Major allergen Can f 1 & 19407 & 56 \\
\hline AP & $\sim 15 \mathrm{KDa}$ & Alpha-1B adrenergic receptor (Fragment) & 46717 & 88 \\
\hline BA & $\sim 72 \mathrm{KDa}$ & Interleukin-6 & 23216 & 58 \\
\hline \multirow[t]{2}{*}{ BB } & $\sim 57 \mathrm{KDa}$ & S-arrestin & 45376 & 46 \\
\hline & & Protein transport protein Sec61 subunit alpha isoform 1 & 52661 & 43 \\
\hline $\mathrm{BC}$ & $\sim 24 \mathrm{KDa}$ & V-type proton ATPase subunit G 1 & 13641 & 54 \\
\hline BD & $\sim 15 \mathrm{KDa}$ & NADH-ubiquinone oxidoreductase chain 3 & 13058 & 45 \\
\hline $\mathrm{BE}$ & $\sim 72 \mathrm{KDa}$ & Serum albumin & 70556 & 56 \\
\hline $\mathrm{BF}$ & $\sim 57 \mathrm{KDa}$ & Hepatocyte growth factor & 83344 & 51 \\
\hline BG & $\sim 24 \mathrm{KDa}$ & Endothelin B receptor & 50829 & 46 \\
\hline BH & $\sim 15 \mathrm{KDa}$ & Colipase & 12597 & 44 \\
\hline \multirow[t]{2}{*}{ BI } & $\sim 72 \mathrm{KDa}$ & Inversin & 120720 & 65 \\
\hline & & S-arrestin & 45376 & 50 \\
\hline BJ & $\sim 57 \mathrm{KDa}$ & NAD-dependent protein deacylase sirtuin-5, mitochondrial & 34547 & 46 \\
\hline BK & $\sim 24 \mathrm{KDa}$ & Major allergen Can f 1 & 19407 & 47 \\
\hline BL & $\sim 15 \mathrm{KDa}$ & Cyclic nucleotide-gated cation channel beta-3 & 89994 & 42 \\
\hline BM & $\sim 72 \mathrm{KDa}$ & NAD-dependent protein deacylase sirtuin-5, mitochondrial & 34547 & 60 \\
\hline $\mathrm{BN}$ & $\sim 57 \mathrm{KDa}$ & ATP-dependent 6-phosphofructokinase, muscle type & 86362 & 54 \\
\hline $\mathrm{BO}$ & $\sim 24 \mathrm{KDa}$ & Major allergen Can f 1 & 19407 & 57 \\
\hline BP & $\sim 15 \mathrm{KDa}$ & Vascular cell adhesion protein 1 & 82501 & 48 \\
\hline
\end{tabular}


day. SIRT5, VCAM-1 were found as major proteins in group A tear whereas IL-6, SAG, SEC61A1, ATP6V1G1 and MT-ND3 were the major proteins expressed in group B. IL- 6 is a potent inducer of acute phase response and plays an essential role in the final differentiation of B-cells into Ig- secreting cells (Tanaka et al., 2014). IL-6 concentration was found significantly high in tear film of patients suffering from Sjogren syndrome (Tishler et al., 1998), in serum and in peripheral circulating lymphocytes of SS patients (Boras et al., 2004), in saliva and labial gland biopsies of SS patients (Tishler et al., 1998; Boras et al., 2004). SAG is a major component of outer segments of photo-pigment rod, its major physiological role being quenching of visual transduction cascade induced by light activation of rhodopsin and may play a role in light dependent degeneration of retinal photoreceptor cells (Granzin et al., 1998). SAG is confined to retina in an immune-privileged location (Craft et al., 1994). It is a potent ocular antigen which can elicit immune response in susceptible hosts (Gery et al., 1986; de Smet et al.,
2001). Predominance of IL-6, SAG and down regulation of tear lipocalin Can $\mathrm{f} 1$ was found in corneal ulcer cases with KCS pathology. VCAM-1 was found up-regulated in group A. Pro-inflammatory response induced by cytokines IL-4 and TNF- $\alpha$ can enhance cellular adhesion molecules ICAM -1 and VCAM-1 in corneal fibroblasts (Okada et al., 2005).

Gene ontology analysis of the tear proteins before and after DPSIS graft in group A and Group B was conducted through the Protein Atlas Through Evolutionary Relationship (PANTHER) classification system (http:// www.pantherdb.org/, SRI International, Menlo Park, CA). Catalytic activity and Binding were the major molecular function in both groups. Molecular function regulators were up-regulated in group B before and after DPSIS grafting. Transporter activity was found increased in both the groups post DPSIS grafting (Fig. 4a, 4b, 4c \& 4d). Cellular process was the most up-regulated biological function in all categories. Biological regulation and

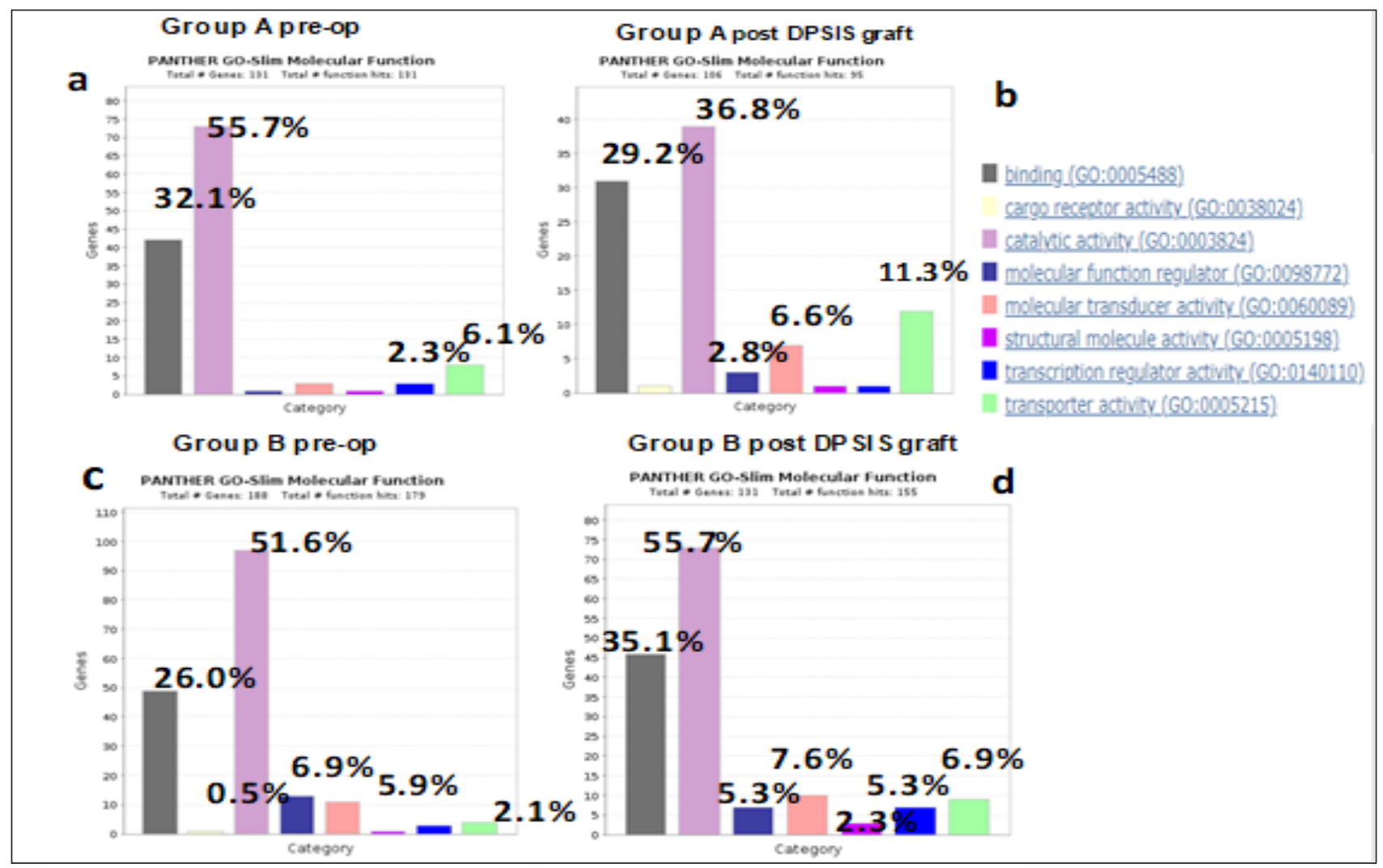

Fig. 4: Gene ontology search on the identified tear proteins for Molecular function in group A before DPSIS graft (a) after DPSIS graft (b) and in Group B before DPSIS graft (c) and after DPSIS graft (d) 


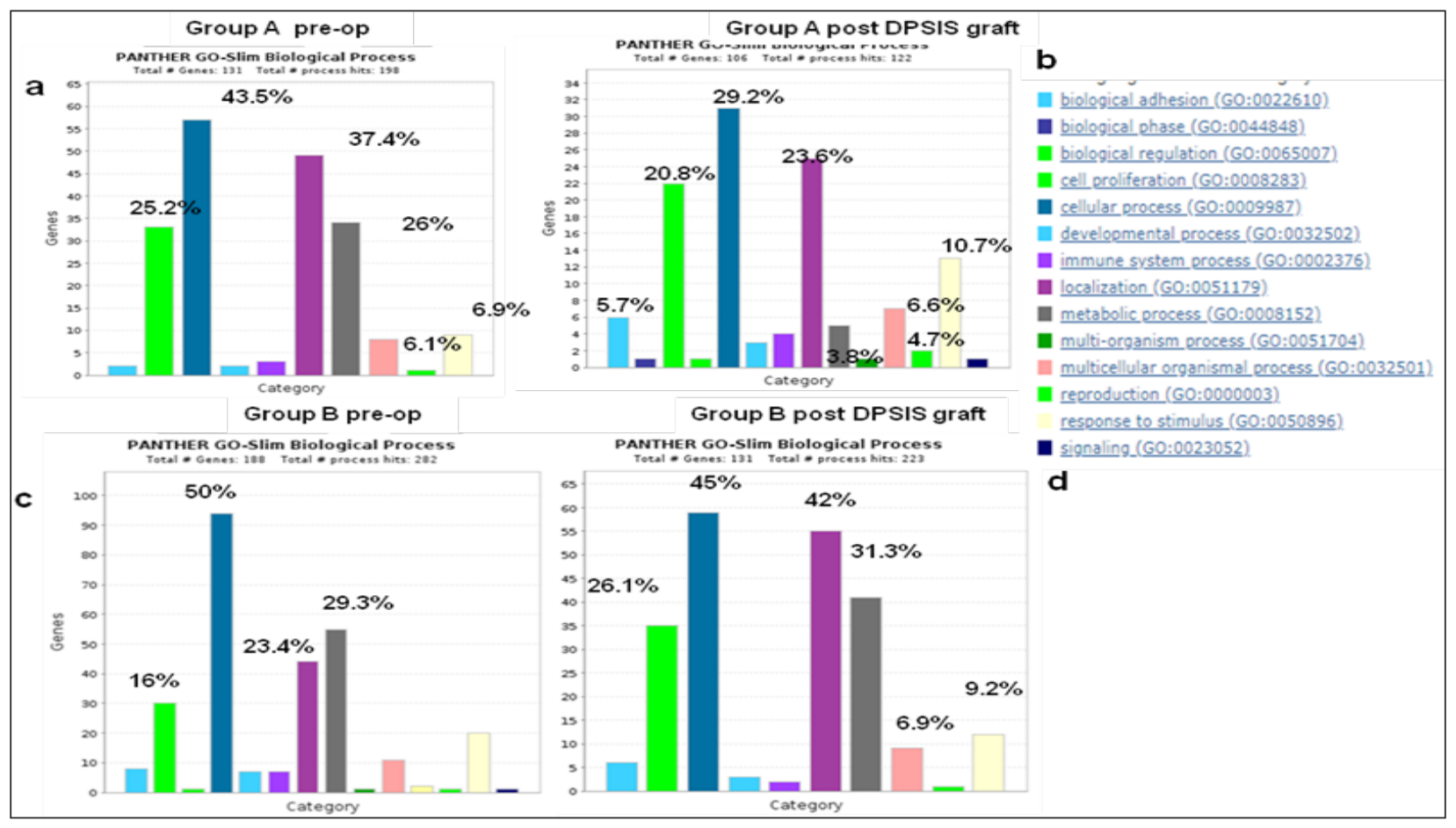

Fig. 5: Gene ontology search on the identified tear proteins for Biological Process in group A before DPSIS graft (a) after DPSIS graft (b) and in Group B before DPSIS graft (c) and after DPSIS graft (d)

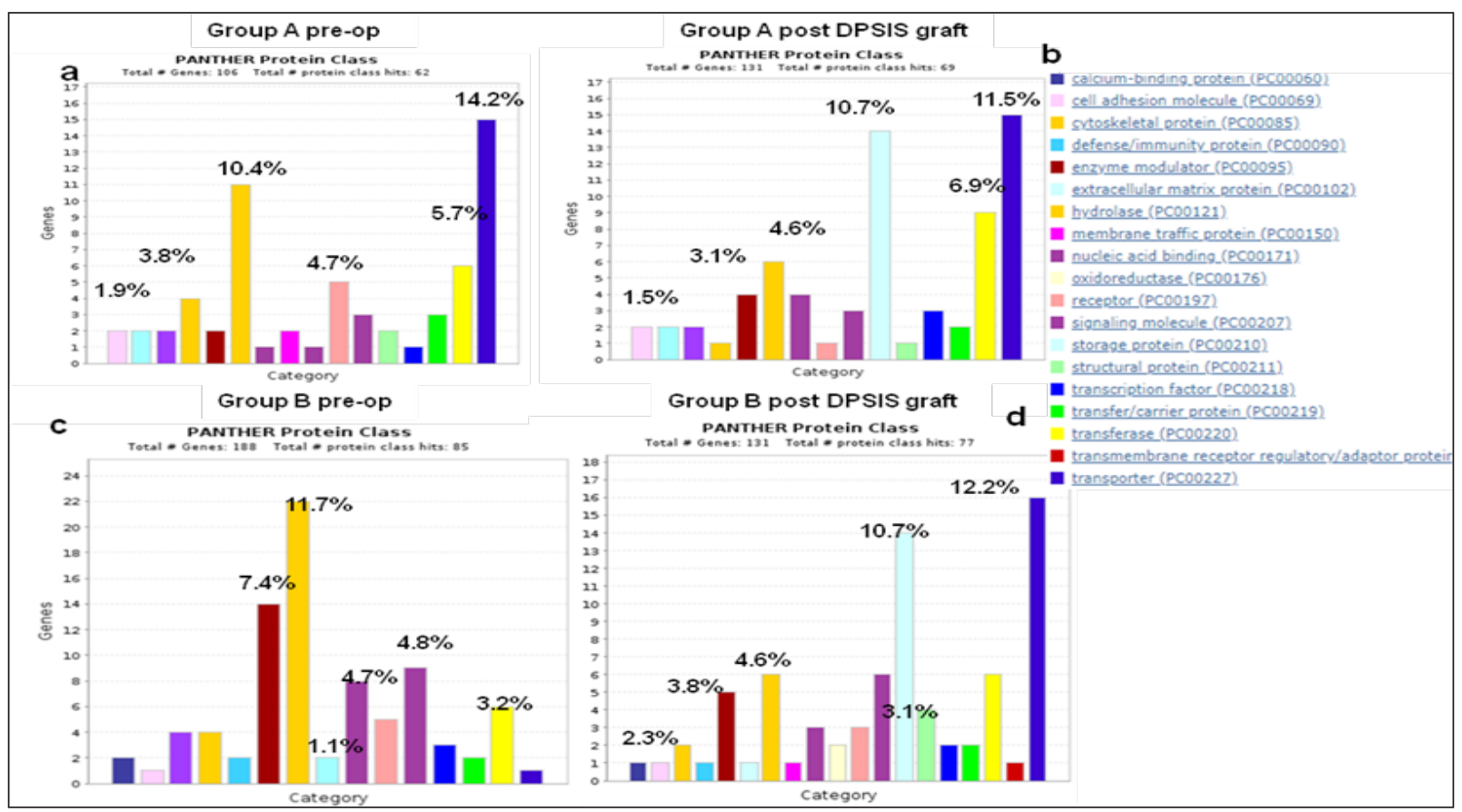

Fig. 6: Gene ontology search on the identified tear proteins for Protein Class in group A before DPSIS graft (a) after DPSIS graft (b) and in Group B before DPSIS graft (c) and after DPSIS graft (d) 


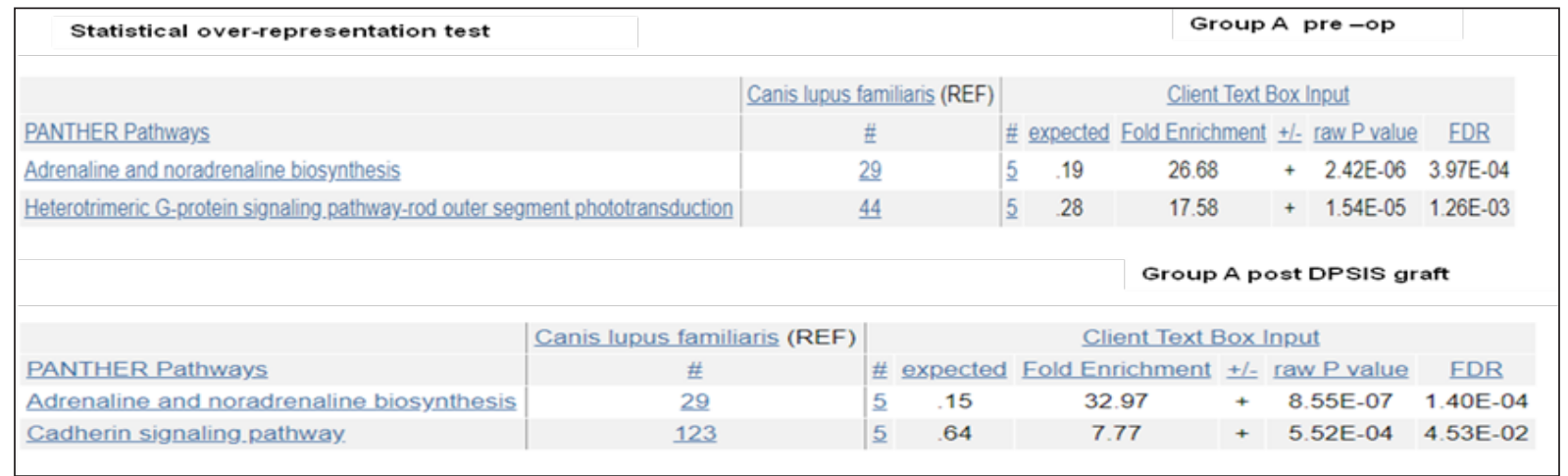

Fig. 7: Statistical overrepresentation of PANTHER pathways in relation to Canis lupus familiaris reference genome in Group A before and after DPSIS graft

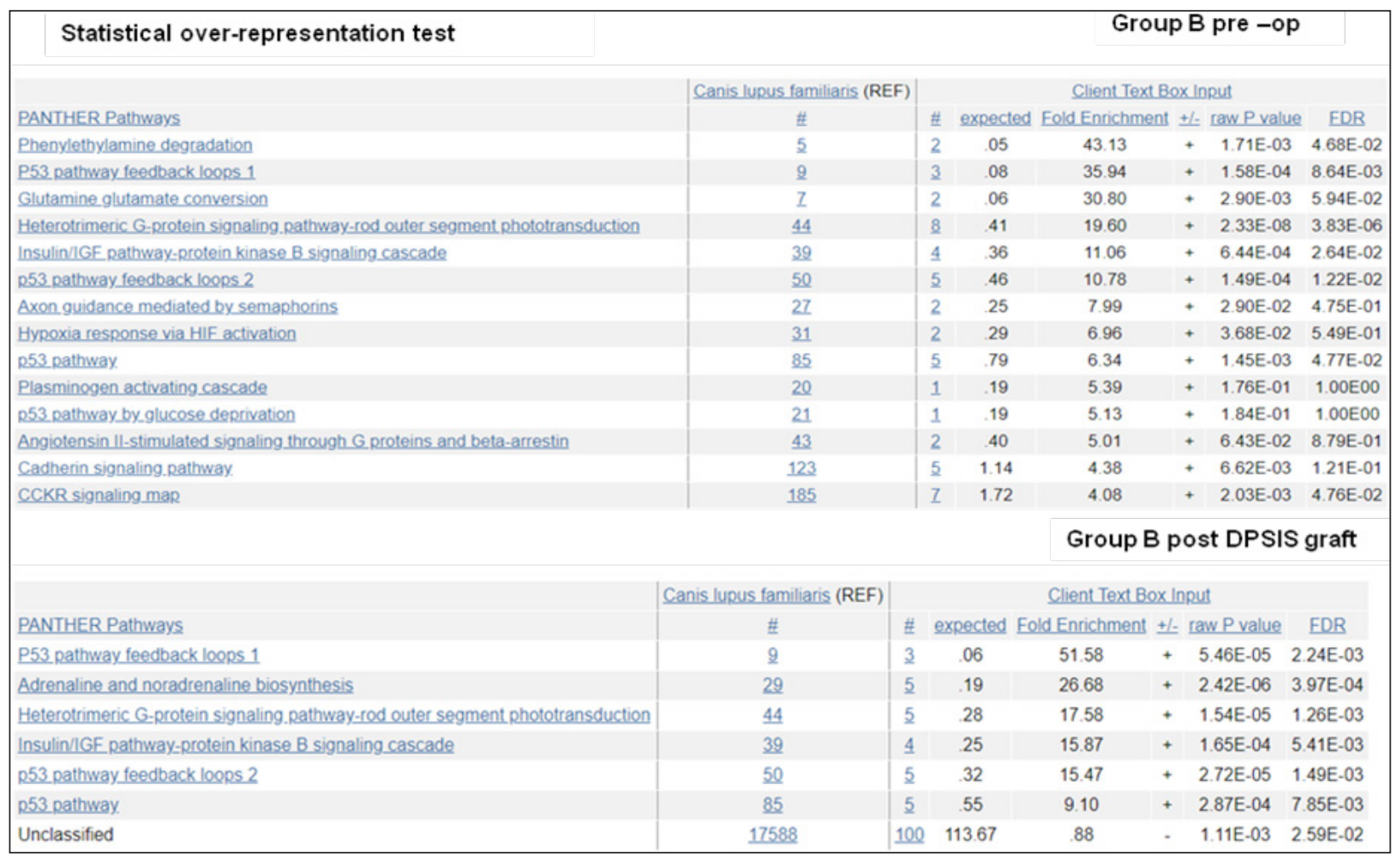

Fig. 8: Statistical overrepresentation of PANTHER pathways in relation to Canis lupus familiaris reference genome in Group B before and after DPSIS graft

localization increased post DPSIS graft in group B whereas cellular process decreased percentagewise. Cell proliferation and signalling proteins increased in Group A post DPSIS graft (Fig. 5a, 5b, 5c \& 5d). Transporters and hydrolases were the major protein class in group A pre op tear whereas hydrolases and enzyme modulators were the major protein class in group B pre op tear.
Transporters were found down regulated in group B pre op tear compared to group A pre op tear. Storage protein and transporters were the major protein class in both groups after DPSIS grafting (Fig. 6a-6d).

Statistical overrepresentation of PANTHER pathways in relation to Canis lupus familiaris reference genome was 
performed through the Protein Atlas Through Evolutionary Relationship (PANTHER) classification system (http:// www.pantherdb.org/, SRI International, Menlo Park, CA) (Fisher exact test with FDR $\mathrm{P}<0.05$ ). A number of pathways were found significantly over represented in Group B before and after DPSIS graft compared to group A which included p53 pathway, p53 pathway feedback loop 1 and 2 (Fig. 8) whereas Cadherin signalling pathway was found over represented in group A post DPSIS graft (Fig. 7). Cellular stress is a major inducer of p53, a tumor suppressor, which under stressors like DNA damage and oncogene activation, gets activated, stabilized and accumulated within cell (Chipuk and Green, 2006; Levine and Oren, 2009).

\section{CONCLUSION}

MALDI-TOF/MS is promising tool to analyse unique protein profile of tear film and hence was employed to understand the molecular mechanism of DSPIS grafting in KCS cases of dogs. Proteomic study of tear film collected from DPSIS graft to repair corneal epithelial defects with $\mathrm{KCS}$ as underlying pathology was suggestive of molecular events such as cellular senescence and apoptosis as underlying mechanisms of KCS pathology and successful graft uptake warranted strategies to face these. Large number of proteins identified through tear film proteomics and key proteins like USP37, KRT1, Major allergen Can F1, CCDC39, PRKCD, Serum albumin, TERT and CD163 were found down regulated in KCS. Protein INVS was found significantly up regulated in group B whereas ZNF252 was found significantly up regulated in group A post DPSIS graft. Clinically DPSIS was well integrated in both KCS and control groups having corneal ulcer, identification of differentially expressed tear proteins helped to highlight disease pathways specific for KCS, hence useful for management of surgical diseases with underlying immune deviation as in corneal ulcer due to KCS.

\section{ACKNOWLEDGEMENTS}

Authors of this manuscript gratefully acknowledge Department of Biotechnology, Government of India (DBT vide G.O. No. BT/ADV/Canine Health/ GADVASU/2017-18) for financial support and, Molecular Biophysics Unit, Indian Institute of Science, Bangalore,
India for Proteomics Facility. Authors also acknowledge laboratory support and facilities offered by various divisions of ICAR-Indian Veterinary Research Institute, Izzatnagar, Bareilly, Uttar Pradesh, India.

\section{REFERENCES}

Allen, E.H., Courtney, D.G., Atkinson, S.D., Moore, J.E., Mairs, L., Poulsen, E.T., Schiroli, D., Maurizi, E., Cole, C., Hickerson, R.P., James, J., Murgatroyd, H., Smith, F.J.D., MacEwen, C., Enghild, J.J., Nesbit, M. A., Leslie, D.M., Pedrioli, W.H.I. and Tara Moore, C.B. 2016. Keratin 12 missense mutation induces the unfolded protein response and apoptosis in Meesmann epithelial corneal dystrophy. Hum. Mol. Genet., 25: 1176-1191.

Andrade, A.L., Laus, J.L., Figueiredo, F. and Batista, C.M. 1999. The use of preserved equine renal capsule to repair lamellar corneal lesions in normal dogs. Vet. Ophthalmol., 2: 79-82.

Boras, V.V., Cikes, N., Lukac, J., Arambasin, A.C., Virag, M. and Bosnjak, A. 2004. The significance of salivary and serum interleukin 6 and basic fibroblast growth factor levels in patients with Sjogren's syndrome. Coll. Anthropol., 28: $305-$ 309

Chipuk, J.E. and Green, D.R. 2006. Dissecting p53-dependent apoptosis. Cell Death Differ., 13: 994-1002.

Colitz, C.M.H., Barden, C.A., Lu, P. and Chandler, H.L. 2006. Ultraviolet irradiation up-regulates telomerase transcription and activity in lens epithelial cells. Vet. Ophthalmol., 9: 379385

Craft, C.M., Whitmore, D.H. and Wiechmann, A.F. 1994. Cone arrestin identified by targeting expression of a functional family. J. Biol. Chem., 269: 4613-4619.

de Smet, M.D., Bitar, G., Mainigi, S. and Nussenblatt, R.B. 2001. Human S-Antigen Determinant Recognition in Uveitis. Invest. Ophthalmol. Vis. Sci., 42(13): 3233-3238.

Deborah, A., Swanson, C.L., Freund, L.P., Roderick, R. and McInnes, D.V. 1996. A Ubiquitin C-Terminal Hydrolase Gene on the Proximal Short Arm of the X Chromosome: Implications for X-Linked Retinal Disorders. Hum. Mol. Genet., 5: 533-538.

Farias, E., Yasunaga, K.L., Peixoto, R.V.R., Fonseca, M.P., Fontes, W. and Galera, P.D. 2013. Comparison of two methods of tear sampling for protein quantification by Bradford method. Pesqui. Vet. Bras., 33: 261-264.

Featherstone, H.J., Sansom, J. and Heinrich, C.L. 2001. The use of porcine small intestinal submucosa in ten cases of feline corneal disease. Vet. Ophthalmol., 4: 147-153.

Gao, X., Gauderman, W.J., Liu, Y., Marjoram, P., Torres, M., Haritunians, T., Kuo, J.Z., Chen, Y.D., 
Allingham, R.R., Hauser, M. A., Taylor, K.D., Rotter, J.L.I. and Varma, R. 2013. A genome-wide association study of central corneal thickness in Latinos. Invest. Ophthalmol. Vis. Sci., 54: 2435-2443.

Gery, I., Mochizuki, M. and Nussenblatt, R.B. 1986. Retinal specific antigen and immunopathogenic processes they provoke. Prog. Retin. Eye Res., 5: 75-109.

Goulle, F. 2012. Use of porcine small intestinal submucosa for corneal reconstruction in dogs and cats: 106 cases. $J$. Small Anim. Pract., 53: 34-43.

Granzin, J., Wilden, U., Choe, H.W., Labahn, J., Krafft, B. and Büldt, G. 1998. X-ray crystal structure of arrestin from bovine rod outer segments. Nature, 391: 918-921.

Huang, Z., Du, C.X. and Pan, X.D. 2018. The use of in-strip digestion for fast proteomic analysis on tear fluid from dry eye patients. PLOS ONE, 13(8): e0200702.

John C., Gopinathan A., Singh, K., Sharma, P., Sowbharenya, C. and Sarangom, S.B. 2018. Clinical evaluation of topical tacrolimus ointment usage in different stages of keratoconjunctivitis sicca in dogs. Turk. J. Vet. Anim. Sci., 42: 259-268.

John, C., Gopinathan, A., Singh, K., Sowbharenya, C., Kumar, N., Sahoo, M. and Agrawal, R.K. 2020. Conjunctival Immunocytochemistry with Interferon Gamma and Caspase 3 for Clinical Staging of Keratoconjunctivitis Sicca (KCS) in Dogs. Int. J. Curr. Microbiol. App. Sci., 9: 2952-2961

Jung, J.H., Ji, Y.W., Hwang, H.S., Oh, J.W., Kim, H.C., Lee, H.K., Kim, K.P. and Pyo, K. 2017. Proteomic analysis of human lacrimal and tear fluid in dry eye disease. Sci. Rep., 7: 13363.

Kim, J.Y., Won, H.J. and Jeong, S.W. 2009. A retrospective study of ulcerative keratitis in 32 dogs. Int. J. Appl. Res. Vet. Med., 7: 27-31.

Kumar, A., Gopinathan, A., Singh, K., Sasikala, R. and Swapana, C.R. 2020. Effect of tacrolimus treatment on tear fluid cytokines of Keratoconjunctivitis sicca affected dogs. Int. J. Curr. Microbiol. App. Sci., 9(9): 3347-3356.

Levine, A.J. and Oren, M. 2009. The first 30 years of p53: growing evermore complex. Nat. Rev. Cancer, 9: 749-758.

Lu, Y., Vitart, V. and Burdon, K.P. 2013. Genome-wide association analyses identify multiple loci associated with central corneal thickness and keratoconus. Nat. Genet., 45: 155-163.

May-Simera, H.L., Wan, Q. and Jha, B.S. 2018. Primary ciliummediated retinal pigment epithelium maturation is disrupted in ciliopathy patient cells. Cell Rep., 22: 189-205.
Okada, N., Fukagawa, K., Takano, Y., Dogru, M., Tsubota, K., Fujishima, H., Matsumoto, K., Nakajima, T. and Saito, H. 2005. The implications of the Upregulation of ICAM1/VCAM-1 Expression of Corneal Fibroblasts on the Pathogenesis of Allergic Keratopathy. Invest. Ophthalmol. Vis. Sci., 46: 4512-4518.

Pekny, M. and Lane, E.B. 2007. Intermediate filaments and stress. Exp. Cell Res., 313: 2244-2254.

Pellegrini, G., Dellambra, E., Paterna, P., Golisano, O., Traverso, C.E., Rama, P., Lacal, P. and Luca, M.D. 2004. Telomerase activity is sufficient to bypass replicative senescence in human limbal and conjunctival but not corneal keratinocytes. Eur. J. Cell Biol., 83: 691-700.

Simons, M., Gloy, J., Ganner, A., Bullerkotte, A., Bashkurov, M., Krönig, C., Schermer, B., Benzing, T., Cabello, O.A., Jenny, A., Mlodzik, M., Polok, B., Driever, W., Obara, T. and Walz, G. 2005. Inversin, the gene product mutated in nephronophthisis type II, functions as a molecular switch between Wnt signaling pathways. Nat. Genet., 37: 537-543.

Singh, K., Gopinathan, A., Sangeetha, P., Kumar, N., Singh, K.P. and Raina O.K. 2016. Development and clinical application of decellularized porcine SIS and cornea for the repair of corneal defects in animals. Indian J. Anim. Sci., 86(12): 1391-1395.

Sowbharenya C, Singh, K., Gopinathan, A., Sarangom, S.B. 2019. Decellularized porcine small intestinal submucosa for the repair of deep corneal ulcer in dogs. Int. J. Adv. Biol. Res., 9(1): 14-18.

Swapana, C.R., Gopinathan, A., Singh, K., Sasikala, R., Kumar, A., Chelladuraai, S., Kumar, N., Sahoo, M. and Agrawal, R.K. 2020. Down-regulation of rho GTPase-activating protein 7 (DLC1) in tear film and modulation of rho GTPase dynamics by Rosuvastatin in dogs suffering from keratoconjunctivitis sicca. J. Anim. Res., 10(6): 889-898.

Tanaka, T., Narazaki, M. and Kishimoto, T. 2014. IL-6 in inflammation, immunity, and disease. Cold Spring Harb. Perspect. Biol., 6: a01629.

Tishler, M., Yaron, I., Geyer, O., Naftaliev, E. and Yaron, M. 1998. Elevated tear interleukin-6 levels in patients with Sjögren syndrome. Ophthalmol., 105: 2327-2329.

Toivola, D.M., Boor, P., Alam, C. and Strnad, P. 2015. Keratins in health and disease. Curr. Opin. Cell Biol., 32: 73-81.

Winiarczyk, M., Winiarczyk, D., Banach, T., Adaszek, L., Madany, J., Mackiewicz, J., Pietras-Ozga, D. and Winiarczyk, S. 2015. Dog tear film proteome in-depth analysis. PLoS One, 10(12): e0144242. 
